\title{
Hemorrhagic Moyamoya Disease during Pregnancy
}

\author{
John C.L. Sun, Margaret Yakimov, Ismail Al-Badawi, Christopher R. Honey
}

\begin{abstract}
Background: Intracranial hemorrhage in pregnant patients with Moyamoya disease is rare. We review the case of one such patient who presented with pre-eclampsia and a catastrophic intracerebral hemorrhage in order to highlight the associated management difficulties. Methods: A case of a pregnant (31 weeks) female brought to the emergency department with hypertension and a progressive decrease in her level of consciousness is presented. She rapidly developed a dilated right pupil and left extensor posturing. A CT scan of her head showed a large putamenal intracerebral hemorrhage. She was intubated, ventilated and given intravenous mannitol and magnesium sulfate. She underwent a simultaneous craniotomy and Cesarean section. Post-operatively the patient's ICP and jugular venous saturation were monitored in the intensive care unit. Results: The patient delivered a $1185 \mathrm{~g}$ infant who did well. The patient's ICP was well controlled until the tenth post-operative day when she developed malignant brain edema and died. Conclusion: This case highlights three important points. First, simultaneous craniotomy and Cesarean section can be performed. Second, intraoperative control of bleeding Moyamoya vessels is described. Third, the difficult post-operative management of these cases is highlighted. The literature regarding Moyamoya disease and pregnancy is reviewed and some recommendations for the management of this rare but potentially deadly condition are presented.
\end{abstract}

RÉSUMÉ: Maladie hémorragique de Moyamoya pendant la grossesse. Introduction: L'hémorragie intracrânienne chez les patientes enceintes présentant la maladie de Moyamoya est rare. Nous revoyons le cas d'une patiente qui s'est présentée avec de la prééclampsie et une hémorragie intracérébrale catastrophique afin de souligner les difficultés rencontrées dans la prise en charge de telles patientes. Méthodes: Il s'agit d'une femme enceinte de 31 semaines qui a été amenée à l'urgence parce qu'elle présentait de l'hypertension et une détérioration progressive de la conscience. Elle a développé rapidement une mydriase à droite et une posture en extension à gauche. Un scan cérébral a montré une hémorragie intracérébrale importante dans le putamen. Elle a été intubée, ventilée et on lui a administré du mannitol intraveineux ainsi que du sulfate de magnésium. Elle a subi simultanément une crâniotomie et une césarienne. Dans les suites postopératoires, on a monitoré sa pression intracrânienne et son niveau de saturation au niveau de la jugulaire aux soins intensifs. Résultats: L'enfant pesait $1185 \mathrm{~g}$ et son évolution a été favorable. La pression intracrânienne de la patiente a été bien contrôlée jusqu'au dixième jour postopératoire alors qu'elle a développé un dème malin du cerveau et elle est décédée. Conclusion: Ce cas illustre trois points importants. Premièrement, on peut faire simultanément une crâniotomie et une césarienne. Deuxièmement, nous décrivons le contrôle du saignement pendant la chirurgie, au niveau des vaisseaux atteints de la maladie de Moyamoya. Troisièmement, nous soulignons les difficultés du traitement postopératoire de ces cas. Nous revoyons la littérature concernant la maladie de Moyamoya et la grossesse ainsi que certaines recommandations pour la prise en charge de cette maladie rare mais potentiellement fatale.

Can. J. Neurol. Sci. 2000; 27: 73-76

Moyamoya disease is a rare cause of intracranial hemorrhage during pregnancy. ${ }^{1-8}$ More common causes include ruptured arterial aneurysms and arterio-venous malformations. ${ }^{9}$ During pregnancy there is an increase in blood volume and cardiac output and later an acute rise in blood pressure during labour. ${ }^{10-12}$ These factors, as well as pre-eclampsia and eclampsia, ${ }^{13}$ may predispose pregnant patients with Moyamoya disease to intracerebral hemorrhage. ${ }^{6,9,14-16}$ We present the case of a pregnant patient with Moyamoya disease who developed preeclampsia and suffered a catastrophic intracerebral hemorrhage. We discuss the neurosurgical and obstetrical management issues pertaining to this case. The literature on pregnancy and Moyamoya disease was reviewed in an attempt to provide some guidelines on managing these patients.

From the Division of Neurosurgery (J.C.L.S, C.R.H.) and Department of Obstetrics and Gynaecology (M.Y., I.A-B.), University of British Columbia, Vancouver, BC, Canada.

RECEIVED MAY 27, 1999. ACCEPTED IN FINAL FORM SEPTEMBER 30, 1999. Reprint requests to: C.R. Honey, Division of Neurosurgery, University of British Columbia, 3rd Floor, 910 West 10th Avenue, Vancouver, B.C. Canada V5Z 4E3. 


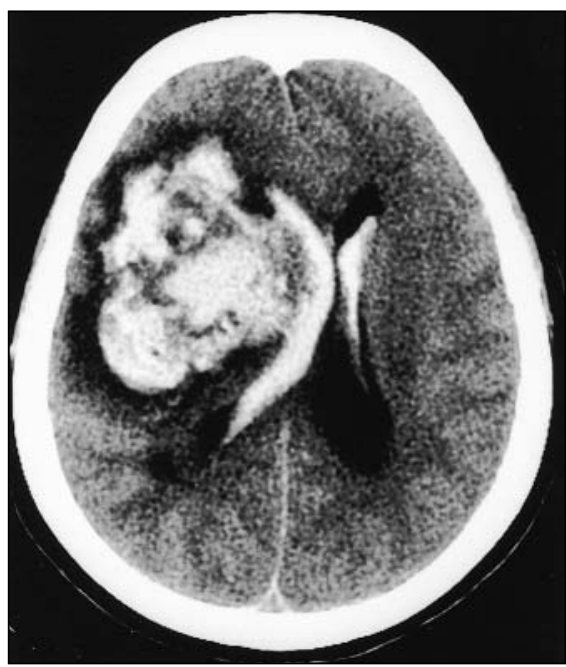

Figure 1: Pre-operative CT scan. A massive intracerebral hemorrhage with intraventricular extension is demonstrated.

\section{CASE REPORT}

A 36-year-old Filipino woman who was 31 weeks pregnant was brought to the emergency department because of a reduced level of consciousness and the sudden development of left hemiparesis. She was gravida three, para zero and had had two spontaneous abortions. Her pregnancy had been uneventful except for high blood pressure that had developed in the previous month. She had been complaining of a generalized headache for two days which became acutely worse on the day of admission. She was noted by her husband to be slurring her speech and she lost consciousness for a few minutes. On transfer to the hospital, the paramedics documented a left hemiparesis with a Glasgow Coma Scale (GCS) of fourteen.

In the emergency department, her level of consciousness deteriorated to a GCS of seven and she developed a dilated right pupil and left extensor posturing. Her blood pressure was $160 / 110 \mathrm{mmHg}$ with a heart

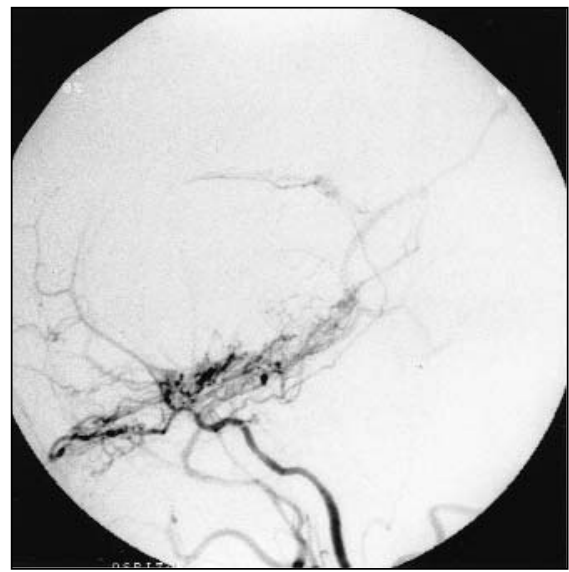

Figure 3: Post-operative angiogram. Lateral view of right internal carotid injection shows poor filling of middle cerebral artery and moyamoya vessels producing the "puff of smoke" effect.

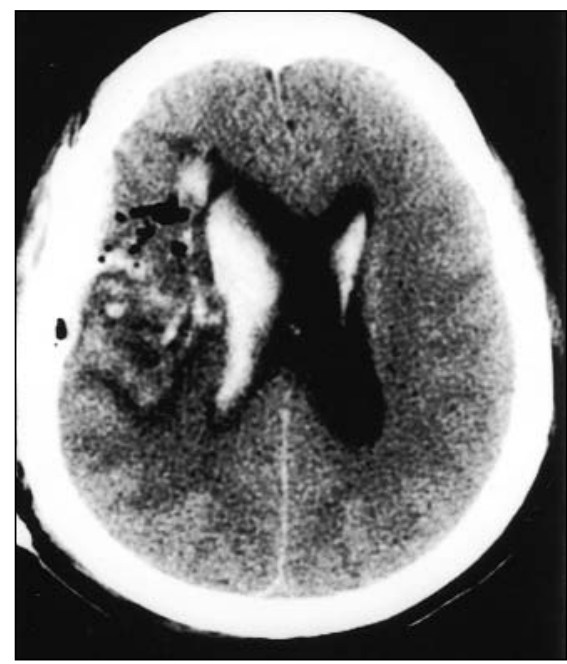

Figure 2: Post-operative CT scan. The clot has been removed with resultant reduction of mass effect and midline shift.

rate of $84 /$ minute. Fetal heart rate monitoring showed a normal baseline fetal heart rate. She was intubated, ventilated and a CT scan of her head showed a large putamenal intracerebral hemorrhage extending into the frontal lobe causing significant mass effect (Figure 1). Intravenous mannitol and magnesium sulfate were given and she was taken directly to the operating room.

An emergency frontal craniotomy and evacuation of the hematoma was performed. A Cesarean section was performed simultaneously in order to interrupt the pre-eclamptic process and thereby improve her blood pressure. The Cesarean section was performed without complication. The craniotomy, however, took six hours to complete because of persistent arterial bleeding. As soon as one area of bleeding was controlled with bipolar cautery another would spontaneously start. Numerous small arterial vessels (diameter $1 \mathrm{~mm}$ ) could be seen coursing through the white matter of the brain. Eventually hemostasis was

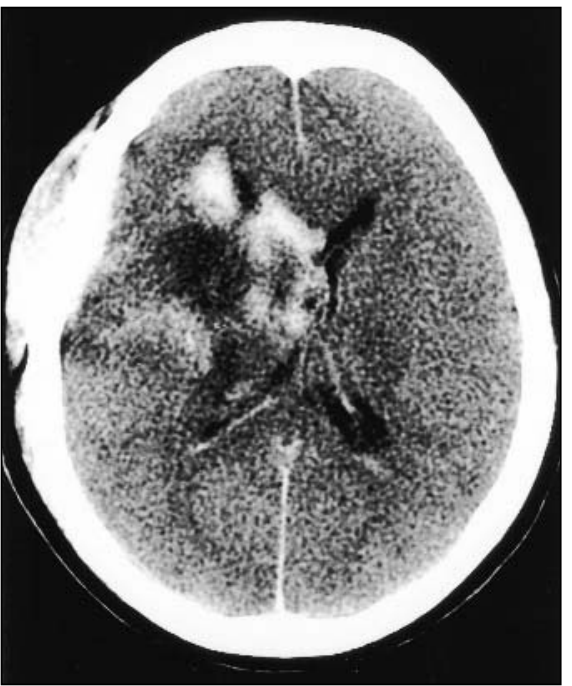

Figure 4: Final CT scan. A wedge-shaped infarct is demonstrated in the area of the hemorrhage. The remaining brain shows loss of gray-white distinction. 
effected but the patient required thirteen units of packed red blood cells, four units of platelets and ten units of cryoprecipitate.

The patient gave birth to a $1185 \mathrm{~g}$ female infant whose weight was at the tenth percentile for gestational age. The baby was intubated and transported to the B.C. Children's Hospital for management and subsequently did very well. Post-operatively, the mother remained unconscious requiring ventilator support. Her GCS was five, with right sided flexor posturing, absent movement on her left side and equal pupils. A post-operative CT scan of the head showed adequate decompression with no evidence of re-accumulation of blood (Figure 2). An external ventricular drain was placed to monitor her intracranial pressure (ICP). Her ICP remained stable (13 to $22 \mathrm{mmHg}$ ) postoperatively and she began to withdraw to pain on both sides (right side stronger than left). An angiogram demonstrated severe Moyamoya Disease involving both the anterior and posterior circulation with no associated aneurysms (Figure 3). Her ICP began to increase on the third day. She was cooled, sedated and pharmacologically paralyzed to control her ICP. She did not develop HELLP syndrome (hemolytic anemia, elevated liver enzymes and low platelets) and her blood pressure was kept within normal limits during her post-operative course. She did have proteinuria and transient thrombocytopenia.

On the tenth post-operative day the paralysis was stopped and she was slowly re-warmed over a few days. Her ICP subsequently became high despite mannitol and resuming a higher level of sedation. A CT scan demonstrated loss of gray-white differentiation and diffuse low density changes (Figure 4). She rapidly lost her brain stem reflexes and was pronounced brain dead several hours later. The family refused an autopsy.

\section{DiscuSSION}

There are several reported cases of patients with Moyamoya disease becoming pregnant. ${ }^{1-7,17-20}$ Careful monitoring of their blood pressure is essential to prevent intracranial complications during the pregnancy and parturition. The optimum blood pressure, however, is unknown. Too low a blood pressure can cause cerebral ischemia because of the arterial stenosis and decreased cerebral blood flow in areas served by these abnormal vessels. $^{21}$ Too high a blood pressure can cause an intracerebral hemorrhage as a result of rupturing an associated aneurysm or the fragile collateral vessels. ${ }^{18,22}$ It is probably best to maintain a normal blood pressure throughout pregnancy and labor, with a systolic blood pressure (SBP) between 100 to $160 \mathrm{mmHg}$ and a diastolic blood pressure (DBP) below $110 \mathrm{mmHg}$ (although a $\mathrm{SBP}$ as high as $180 \mathrm{mmHg}$ and a DBP as high as $124 \mathrm{mmHg}$ has been tolerated $\left.{ }^{18}\right)$. Antihypertensives such as hydralazine or labetalol and pressors such as ephedrine should be available to control the blood pressure. ${ }^{18,23}$

Close obstetrical management will detect pre-eclampsia which may increase the risk of an intracranial hemorrhage. ${ }^{8,9,13,14,24-29}$ It may be necessary, if pre-eclampsia becomes severe, to facilitate delivery in order to reduce blood pressure and prevent intracranial hemorrhage. ${ }^{20}$ We would recommend delivery by Cesarean section if i) rapid control of blood pressure is required, ii) the mother's condition is unstable (eg. intracranial hemorrhage) or iii) fetal distress is detected. If delivery is by Cesarean section, general anesthetic should be utilized as this provides a more controlled cerebral perfusion by preventing hyperventilation and reducing fluctuations in blood pressure. ${ }^{18-20,30}$

Vaginal delivery in a patient with Moyamoya disease can be successful if the pregnancy has proceeded without complica- tion. ${ }^{18}$ Continuous monitoring of the blood pressure with an arterial line ${ }^{18}$ and the use of an epidural or local anesthetic with a vacuum or forceps-assisted delivery is recommended..$^{9,14,18}$ These recommendations are similar to those for pregnant patients with arteriovenous malformations or unsecured aneurysms. ${ }^{15,16,23,31}$

In the case of our patient, it was decided to perform a simultaneous craniotomy for evacuation of the intracerebral hematoma and Cesarean section to rapidly treat the preeclampsia and remove the fetus from the immediate danger of the mother's unstable condition. One case of simultaneous craniotomy and Cesarean section ${ }^{29}$ and a few cases of craniotomy and subsequent Cesarean section have been described. ${ }^{25,32-34}$ In these cases there were no complications related to performing these two operations together. It is recommended that adequate blood, platelets and plasma for transfusion be available in case of excessive blood loss or the development of disseminated intravascular coagulation. Maternal osmotic diuretics must be used with caution because it may reduce placental blood flow. ${ }^{9,15}$

Control of intra-cerebral bleeding in patients with Moyamoya disease is difficult because of the friable nature of the collateral vessels. Persistence is the key and the vessels will eventually seal with bipolar coagulation or miniclips. It is preferable to avoid disturbing these vessels and a subtotal debulking of the hematoma may be wise.

The post-operative care of our patient focused on maintaining i) normal cerebral perfusion (evaluated by mean arterial pressure, ICP and jugular venous oxygen extraction),

ii) normal ICP (monitored by external ventricular drain), and

iii)electrolyte and coagulation homeostasis. Control of blood pressure in the post-operative period was aimed at preventing both ischemia from hypoperfusion or rebleeding from hypertension. Seizure prophylaxis was used to reduce the chance of cerebral ischemia. ${ }^{7}$ The required duration of paralysis, cooling and sedation to control possible elevated ICP is unknown. We felt ten days would be enough but the uncontrolled rise in her ICP following re-warming suggests it may not have been. Moyamoya vessels do not demonstrate normal autoregulatory responses. ${ }^{35,36}$

In summary, pregnant patients with Moyamoya disease require special care. They need counseling prior to pregnancy and careful management during pregnancy to detect preeclampsia or other blood pressure changes. A vaginal delivery is possible but complications may require a Cesarean section under general anesthetic. In the event of life threatening intracranial hemorrhage, a craniotomy (with or without Cesarean section) can be performed. Surgeons are warned of the torrential hemorrhage that can occur if the Moyamoya vessels are disturbed.

\section{ACKNOWLEDGMENTS}

The authors thanks the members of the VGHNA for their continued support.

\section{REFERENCES:}

1. Takagi T, Ushimaru N, Hirata M. [A case of "moyamoya" disease found out after cesarean section.] Sanka To Fujinka 1977; 44: 949-954. 
2. Fujita K, Yamasaki S, Tamaki N, et al. [Cerebro-vascular accident during pregnancy.] No Shinkei Geka 1978; 6: 989-995.

3. Karasawa J, Kikuchi H, Furuse S. Treatment of moyamoya disease with STA-MCA anastomosis. J Neurosurg 1978; 49: 679-688.

4. Karasawa J, Kikuchi H, Furuse S. Subependymal hematoma in "moyamoya" disease. Surg Neurol 1980; 13: 118-120.

5. Enomoto H, Goto H. Moyamoya disease presenting as intracerebral hemorrhage during pregnancy: case report and review of the literature. Neurosurgery 1986; 20: 33-35.

6. Hashimoto K, Fujii K, Nishimura K, et al. Occlusive cerebrovascular disease with moyamoya vessels and intracranial hemorrhage during pregnancy. Neurol Med Chir 1988; 28: 588-593.

7. Amin-Hanjani S, Kuhn M, Sloane N, et al. Moyamoya disease in pregnancy: a case report. Am J Obstet Gynecol 1993; 169: 395-396.

8. Komiyama M, Yasui T, Kitano S, et al. Moyamoya disease and pregnancy: case report and review of the literature. Neurosurgery 1998; 43: 360-369.

9. Dias MS, Sekhar LN. Intracranial hemorrhage from aneurysms and arteriovenous malformations during pregnancy and the puerperium. Neurosurgery 1990; 27: 855-866.

10. Hendricks $\mathrm{CH}$. The hemodynamics of a uterine contraction. Am J Obstet Gynecol 1958; 76: 969-982.

11. Kerr MG. Cardiovascular dynamics in pregnancy and labour. $\mathrm{Br}$ Med Bull 1968; 24: 19-24.

12. Ueland K, Hansen J. Maternal cardiovascular dynamics: II. Posture and uterine contractions. Am J Obstet Gynecol 1969; 103: 1-18.

13. Sharshar T, Lamy C, Mas JL. Incidence and causes of strokes associated with pregnancy and puerperium. Stroke 1995; 26: 930-936.

14. Amias AG. Cerebral vascular disease in pregnancy: I. Hemorrhage. J Obstet Gynecol Br Commonw 1970; 77: 100-120.

15. Robinson JL, Hall CJ, Sedzimir CB. Subarachnoid hemorrhage in pregnancy. J Neurosurg 1972; 36:27-33.

16. Robinson JL, Hall CJ, Sedzimir CB. Arteriovenous malformations, aneurysms, and pregnancy. J Neurosurg 1974; 41: 63-70.

17. Matsuoka M, Kamata T, Okuba H. [Pregnancy and delivery of the patient with moyamoya disease.] Sanfujinka Chiryo 1976; 33: 572-575.

18. Bingham WF, Beguin EA, Ramirez-Lessepas M. Moyamoya disease in pregnancy. Wis Med J 1980; 79: 21-25.

19. Sasaki J, Mezaki N. [Considerations concerning the management of pregnancy and delivery in "moyamoya" disease.] Sanka To Fujinka 1984; 51: 109-116.

20. Miyakawa I, Lee HC, Haruyama Y, et al. Occlusive disease of the internal carotid arteries with vascular collaterals (moyamoya disease) in pregnancy. Arch Gynecol 1986; 237: 175-180.
21. Ogawa A, Yoshimoto T, Suzuki J, et al. Cerebral blood flow in moyamoya disease. Part 1: correlation with age and regional distribution. Acta Neurochir 1990; 105: 30-34.

22. Kawaguchi S, Sakaki T, Kakizaki T, et al. Clinical features of the haemorrhage type moyamoya disease based on 31 cases. Acta Neurochir 1996; 138: 1200-1210.

23. Viscomi CM, Wilson J, Bernstein I. Anesthetic management of a parturient with an incompletely resected cerebral arteriovenous malformation. Reg Anesth 1997; 22: 192-197.

24. Colosimo Jr C, Fileni A, Guerrini P. CT findings in eclampsia. Neuroradiology 1985; 27: 313-317.

25. Lazebnik N, Pazmino R, Dierker LR, et al. Maternal intracranial hemorrhage complicating severe superimposed pre-eclampsia. J Reprod Med 1989; 34: 857-860.

26. Vandenplas O, Dive A, Dooms G, et al. Magnetic resonance evaluation of severe neurologic disorders in eclampsia. Neuroradiology 1990; 32: 47-49.

27. Digre KB, Varner MW, Osborn AG, et al. Cranial magnetic resonance imaging in severe pre-eclampsia vs eclampsia. Arch Neurol 1993; 50: 399-406.

28. Drislane FW, Wang A. Multifocal cerebral hemorrhage in eclampsia and severe pre-eclampsia. J Neurol 1997; 244: 194-198.

29. Giannina G, Smith D, Belfort MA, et al. Atraumatic subdural hematoma associated with pre-eclampsia. J Matern Fetal Med 1997; 6: 93-95.

30. Maymon R, Fejgin M. Intracranial hemorrhage during pregnancy and puerperium. Obstet Gynecol Surv 1990; 45:157-159.

31. Hunt HB, Schifrin BS, Suzuki K. Ruptured berry aneurysms and pregnancy. Obstet Gynecol 1974; 43: 827-837.

32. DeGrood RM, Beemer WH, Fenner DE, et al. A large meningioma presenting as a neurologic emergency in late pregnancy. Obstet Gynecol 1987; 69: 439-440.

33. D'Haese J, Christiaens F, D'Haens J, et al. Combined cesarean section and clipping of a ruptured cerebral aneurysm: a case report. J Neurosurg Anesthesiol 1997; 9: 341-345.

34. Korula G, Farling P. Anesthetic management for a combined cesarean section and posterior fossa craniectomy. J Neurosurg Anesthesiol 1998; 10: 30-33.

35. Ogawa A, Nakamura N, Yoshimoto T, et al. Cerebral blood flow in moyamoya disease. Part 2: autoregulation and $\mathrm{CO}_{2}$ response. Acta Neurochir 1990; 105: 107-111.

36. Kuwabara Y, Ichiya Y, Sasaki M, et al. Response to hypercapnia in moyamoya disease. Cerebrovascular response to hypercapnia in pediatric and adult patients with moyamoya disease. Stroke 1997; 28: 701-707. 